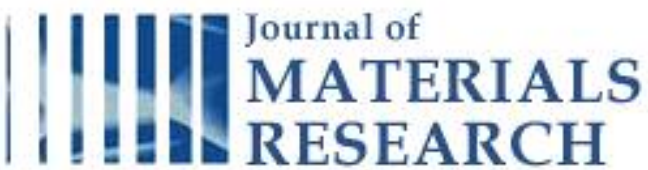

Viscoelastic and Poroelastic Mechanical Characterization of Hydrated Gels

\begin{tabular}{|r|l|}
\hline Journal: & Journal of Materials Research \\
\hline Manuscript ID: & draft \\
\hline Manuscript Type: & Focus Issue: Indentation Methods in Advanced Materials Research \\
\hline Date Submitted by the \\
Author: & $\mathrm{n} / \mathrm{a}$ \\
\hline Complete List of Authors: & $\begin{array}{l}\text { Galli, Matteo; Cambridge University, Engineering Dept. } \\
\text { Comley, Kerstyn; Cambridge University, Engineering Dept. } \\
\text { Shean, Tamaryn; Cambridge University, Engineering Dept. } \\
\text { Oyen, Michelle; Cambridge University, Dept of Engineering }\end{array}$ \\
\hline Key Words: & elastic properties, nano-indentation, water \\
\hline
\end{tabular}

\section{S) Scholarone}

Manuscript Central 
Page 1 of 22

\title{
Viscoelastic and Poroelastic Mechanical Characterization of Hydrated Gels
}

\author{
Matteo Galli, Kerstyn S.C. Comley, Tamaryn A.V. Shean, Michelle L. Oyen \\ Cambridge University Engineering Dept. \\ Cambridge, CB2 1PZ, UK
}

\section{Address Correspondence to:}

Dr Michelle L. Oyen

Cambridge University Engineering Dept., Trumpington St.,

Cambridge, CB2 1PZ, UK

phone: +44 (0)1223 332680

fax: +44(0)1223 332662

email:mlo29@cam.ac.uk

\section{Submitted to:}

Journal of Materials Research,

Focus Issue: Instrumented Indentation

Submitted 8/10/2008 
Page 2 of 22

\begin{abstract}
Measurement of the mechanical behavior of hydrated gels is challenging due to a relatively small elastic modulus and dominant time-dependence compared with traditional engineering materials. Here polyacrylamide gel materials are examined using different techniques (indentation, unconfined compression, dynamic mechanical analysis) at different length-scales and considering both viscoelastic and poroelastic mechanical frameworks. Elastic modulus values were similar for nanoindentation and microindentation, but both indentation techniques overestimated elastic modulus values compared with homogeneous loading techniques. Hydraulic and intrinsic permeability values from microindentation tests, deconvoluted using a poroelastic finite element model, were consistent with literature values for gels of the same composition. Although elastic modulus values were comparable for viscoelastic and poroelastic analyses, timedependent behavior was length-scale dependent, supporting the use of a poroelastic, instead of a viscoelastic, framework for future studies of gel mechanical behavior under indentation.
\end{abstract}

\title{
KEYWORDS
}

elastic properties, nano-indentation, water, 
Page 3 of 22

\section{INTRODUCTION}

Nanoindentation has become a common technique for characterizing the mechanical properties of a wide range of materials, including materials with timedependent mechanical behavior such as polymers [1] and biological materials [2]. Until recently, the majority of nanoindentation studies concerning biological tissues were on stiff, hard mineralized tissues, and most samples were dehydrated for testing. An increasing interest in compliant, soft and hydrated materials has driven the development of new techniques for expanding nanoindentation to new experimentally challenging materials sets. Both hydrated soft tissues and hydrated gel materials have been the subjects of recent nanoindentation investigations.

Time-dependent mechanical behavior is a critical aspect of the mechanical response in many compliant and hydrated materials. Early nanoindentation studies emphasized time-independent, elastic-plastic material responses but many recent studies have incorporated viscoelastic [3-7] or viscous-elastic-plastic [8,9] material models. Linearly viscoelastic material characterization is now well-developed for nanoindentation studies on glassy and rubbery polymers, and such analysis has been used (with caveats) for characterizing time-dependent nanoindentation creep responses in hydrated bone $[10,11]$ and indentation load-relaxation responses in soft biological tissues $[12,13]$. A similar analysis based on linear viscoelasticity has also been used recently for nanoindentation load-relaxation in hydrated gel materials [14].

Several open questions remain in the viscoelastic literature that are relevant in developing novel mechanical characterization paradigms for hydrated compliant materials. One question concerns the utility of time-domain [3-14] versus frequency domain [15-17] nanoindentation measurements for best-practice mechanical characterization of time-dependent materials. A second question concerns the appropriateness of viscoelastic material models for gels or hydrated tissues, as the behavior of a fluid-saturated porous solid is more appropriately described by poroelasticity $[18,19]$ than viscoelasticity [20]. A recent study examined poroelastic data analysis for bone and demonstrated some promise for identification of hydraulic permeability values from nanoindentation data [21]. 
The current study was undertaken to examine the time-dependent mechanical response of hydrated gel materials, as a model for hydrated soft tissues, via spherical indentation experiments. Both nanoindentation and microindentation load-relaxation studies were performed on gels of two different nominal thicknesses. Data were examined in both viscoelastic and poroelastic mechanical frameworks. Results were compared with two sets of compression tests on the same gels but emphasizing frequency-domain measurements and including dynamic mechanical analysis (DMA). Time-domain indentation relaxation results were converted to storage modulus for comparison with the compression results.

\section{MATERIALS AND EXPERIMENTAL METHODS}

\subsection{Materials}

Polyacrylamide gels were synthesized with $20 \%$ acrylamide following established recipes. Briefly, the gels were created by the addition of initiators (ammonium persulfate and tetramethylethylenediamine (TEMED)) to a $30 \%(\mathrm{w} / \mathrm{v})$ acrylamide stock solution with a 19:1 acrylamide to bis-acrylamide ratio (Severn Biotech Ltd., Kidderminster, Worcs, UK). Gels were cast into two thicknesses (l), nominally $2 \mathrm{~mm}$ and $5 \mathrm{~mm}$ thick and left 24 hours prior to being removed from original casting plates and submerged in distilled water. Gels were kept hydrated by storage in distilled water with water changes approximately every 48 hours until the time of testing.

Dehydration profiles were established by weighing the samples as they air dried; no change of mass was found in the first hour after removal from the bath, and thus tests undertaken in non-submerged conditions were conducted no more than 60 minutes after removal of the gels from the storage bath. Air-dehydrated gels were dehydrated in ambient conditions at least 24 hours prior to testing. Ethanol-dehydrated gels were soaked in ethanol baths for 24 hours prior to testing.

\subsection{Indentation Tests}

Nanoindentation tests were performed in displacement-control on a UBI nanoindenter (Hysitron, Inc., Minneapolis, MN) using the "manual method" for surface determination and test engagement [14]. A spherical alumina indenter tip with a $400 \mu \mathrm{m}$ 
Page 5 of 22

radius was used for all tests. A ramp-hold displacement-time profile was used with a 5 or 10 second ramp time and a 20-30 s hold time for each test. Peak displacements for nanoindentation ranged from 1 to $3.5 \mu \mathrm{m}$.

Microindentation tests were conducted on an Instron 5544 (Canton, MA) under similar ramp-hold conditions with a $10 \mathrm{~s}$ ramp time and a $300 \mathrm{~s}$ hold time, and peak displacements from 100 to $500 \mu \mathrm{m}$ in thin gels and $100 \mu \mathrm{m}$ to $1 \mathrm{~mm}$ in thick gels. The indenter tip was stainless steel and had a $1.5 \mathrm{~mm}$ radius; a $5 \mathrm{~N}$ load cell was used for data collection.

Indentation data for both nanoindentation and microindentation were analyzed with an approximate solution for spherical indentation load-relaxation based on elasticviscoelastic correspondence as presented previously [12]. Briefly, load-time data were fit (nonlinear curve fit wizard, Origin 8, OriginLab, Northampton, MA) to an exponential decay function of the form:

$$
P(t)=B_{\infty}+B_{\mathrm{D}} \exp \left(-t / \tau_{1}\right)
$$

which was derived assuming the extensional relaxation function for a standard linear solid (Figure 1) where the single time-constant exponential decay can be written

$$
E(t)=E_{\infty}+E_{\mathrm{D}} \exp (-t / \tau)
$$

and where the time constant is related to the viscosity and dashpot-associated modulus by $\tau=\eta / E_{1}$. The parameters $E_{\infty}$ and $E_{\mathrm{D}}$ were simply calculated from the fitting parameters $B_{\infty}$ and $B_{\mathrm{D}}$ (assuming $v=0.5$ ) by [12]:

$$
E_{\infty}=\frac{B_{\infty}}{h_{\max }^{3 / 2}(16 \sqrt{R} / 9)}
$$

and

$$
E_{\mathrm{D}}=\frac{B_{\mathrm{D}}}{(R C F) h_{\text {max }}^{3 / 2}(16 \sqrt{R} / 9)},
$$

where

$$
R C F=\frac{\tau}{t_{R}}\left[\exp \left(t_{R} / \tau\right)-1\right]
$$

$E_{\infty}$ is the equilibrium modulus while the instantaneous modulus is given by the $\operatorname{sum} E_{\infty}+$ $E_{\mathrm{D}}$; the elastic fraction is $f_{\mathrm{E}}=E(\infty) / E(0)=E_{\infty} /\left(E_{\infty}+E_{\mathrm{D}}\right)$. 
Page 6 of 22

\subsection{Unconfined compression Tests}

A circular cylinder of the thick (nominally $5 \mathrm{~mm}$ ) diameter $18 \mathrm{~mm}$ was compressed between plastic platens using a screw driven tensile test machine (Instron 5544, Canton, MA) fitted with a $5 \mathrm{~N}$ load cell. An oscillatory saw tooth displacement profile with a peak to peak displacement of $0.3 \mathrm{~mm}$ was used to compress the sample at a range of frequencies from $0.01 \mathrm{~Hz}$ to $8 \mathrm{~Hz}$. A preload of $3 \mathrm{~N}$ was applied to ensure that the sample was held in compression throughout the duration of the test. The raw force, $F(t)$, and displacement, $u(t)$, time series data were converted into the frequency domain, $F(\omega)$ and $u(\omega)$, using a fast Fourier transform. The complex modulus of the sample was calculated as:

$$
E^{*}=\frac{F(\omega) \cdot l}{u(\omega) \cdot A}
$$

where $l$ is the sample height and $A$ is the surface area of the sample; the real part of $E^{*}$ corresponds to the storage modulus $E^{\prime}$ and the imaginary part to the loss modulus $E^{\prime \prime}$.

\subsection{DMA tests}

Dynamic Mechanical Analysis (DMA) in compression was undertaken on circular cylindrical samples of diameter $18 \mathrm{~mm}$ and thickness nominally $5 \mathrm{~mm}$ using a DMA machine (Q800, TA Instruments, Newcastle, DE). The samples were oscillated up to a peak displacement of $5 \mu \mathrm{m}$ over a frequency range of $1-200 \mathrm{~Hz}$. Following the findings of Yamashita [22] a pilot study was undertaken to determine an appropriate static preload of $8.5 \mathrm{~N}$, which gave stable measurements of the complex modulus. During the main compression testing it was noted that at each given frequency a settling time of approximately one minute was required to achieve a stable measurement of the compression storage modulus, $E^{\prime}$ and loss modulus, $E^{\prime \prime}$.

\subsection{Comparisons for time- and frequency domains}

Comparisons were made between indentation and unconfined compression tests by converting the indentation creep function data to storage modulus $\left(E^{\prime}\right)$ and loss tangent $(\tan \delta)$ via [20]: 
Page 7 of 22

$$
\begin{aligned}
& E^{\prime}(\omega)=E_{\infty}+E_{\mathrm{D}} \frac{\omega^{2} \tau^{2}}{1+\omega^{2} \tau^{2}} \\
& \tan \delta(\omega)=\frac{E^{\prime \prime}(\omega)}{E^{\prime}(\omega)}
\end{aligned}
$$

where

$$
E^{\prime \prime}(\omega)=E_{\mathrm{D}} \frac{\omega \tau}{1+\omega^{2} \tau^{2}}
$$

The frequency-based functions were computed using the average values of $E_{\infty}, E_{\mathrm{D}}$ and $\tau$ for the microindentation and nanoindentation tests on similar (thick) samples as were used in the homogeneous compression tests.

\section{MODELING AND ANALYSIS}

An axisymmetric finite element (FE) model of the indentation experiment was developed using ABAQUS (Version 6.7, SIMULIA, Providence, RI, USA). The indenter was modeled as an analytical rigid surface and the contact between the indenter as the specimen surface was imposed to be frictionless (Figure 2). The specimen was assumed to be linear poroleastic and saturated and was discretized using eight-node elements with biquadratic displacement interpolation, bilinear pore pressure interpolation, and reduced integration (the mesh consisted of 65830 nodes and 21735 elements). It was assumed that the specimen lies on an impervious stiff substrate and that water can diffuse freely across the entire layer surface, including the contact region.

The mechanical behavior of a linear poroelastic material saturated with an incompressible fluid depends the elastic properties (in the present case drained elastic modulus, $E$ and Poisson's ratio, $\nu$ were considered) and on the hydraulic permeability $\kappa$ [19]. The intrinsic permeability $k=\eta_{\mathrm{W}} \kappa$, where $\eta_{\mathrm{W}}$ is the viscosity of water. (For further background on poroelasticity the reader is referred to references $[18,19,21]$.) To assess the values of these three material parameters from the results of indentation tests an identification algorithm was utilized.

Given the output of the experiment in terms of indenter time-load data points $\left(t_{1}\right.$, $\left.P_{1}\right), \ldots,\left(t_{m}, P_{m}\right)$ and the model of the experiment $M(\boldsymbol{x}, t)$, whose response is governed by 
a set of unknown parameters $\boldsymbol{x}$, it is possible to compute the residuals for any choice of the parameter values:

$$
f_{i}(\mathbf{x})=\frac{P_{i}-M\left(\mathbf{x}, t_{i}\right)}{P_{\mathrm{ave}}}, i=1, \ldots, m
$$

where $P_{\text {ave }}$ is the average experimental value. In the present case $M(x, t)$ is the finite element model, and the unknown parameters $\boldsymbol{x}$ are $E, v$ and $\kappa$.

For a least squares fit, the objective of the identification procedure is then finding the set of parameters $\boldsymbol{x}$ which minimizes

$$
F(\mathbf{x})=\frac{1}{2} \sum_{i=1}^{m}\left(f_{i}(\mathbf{x})\right)^{2}
$$

Therefore the identification problem becomes the problem of the minimization of the objective function $F(\boldsymbol{x})$ with respect to the unknown parameters $\boldsymbol{x}$. In the present work the minimization problem was solved by using MATLAB (The MathWorks, Natick, MA, US) optimization toolbox and in particular the nonlinear least-squares routine, whose successful use in similar problems is reported in literature [23-25].

Identification was carried out for the hold segment of eight microindentation tests, five on thin gels and three on thick gels. No maximum value of $F(\boldsymbol{x})$ was imposed as convergence criterion and the identification loop was iterated until the procedure showed no improvement in the minimization of $F(\boldsymbol{x})$. Typically convergence was achieved in 4-5 iterations.

\section{RESULTS}

Representative load-time $(P-t)$ relaxation curves are shown in Figure 3 for (a) nanoindentation of a hydrated gel, (b) nanoindentation of dehydrated (ethanol-soaked) gel and (c) microindentation of hydrated gel. On this time-scale, the microindentation results are nearly elastic, while there is some relaxation present in the nanoindentation data on the same time-scale. Interestingly, the dehydrated sample (Fig. 3b), although orders of magnitude stiffer than the hydrated sample tested under the same conditions (Fig. 3a), exhibited more viscous dissipation than the hydrated samples.

Numerical data derived from viscoelastic analysis of the full set of nanoindenation and microindentation tests are shown in Table 1. As was evident in the 
raw load-time responses (Fig. 3), dehydration increased the elastic modulus by three orders of magnitude regardless of dehydration method - air or immersion in ethanol. The elastic fraction $\left(f_{\mathrm{E}}\right)$ decrease was greater in the ethanol-soaked gels compared with the air-dried gels.

Overall the calculated storage modulus values from indentation were greater than those measured in two different modes of homogeneous compression tests, unconfined compression and DMA compression (Figure 4a). Loss tangent values (Fig. 4b) were comparable for both compression tests, and similar to the peak calculated for nanoindentation. In the low frequency range for this experiment, the loss tangent from microindentation also started to approach the compressive values. It is clear that the standard linear solid model (Fig. 1) is too simple a description of the dynamic behavior for these gel materials, given the sharp peak at a single frequency value.

A representative fit to experimental microindentation data from the poroelastic FE model is shown in Figure 5. Summary data from eight poroelastic FE fits to thick and thin gel microindentation tests are shown in Table 2. The drained elastic modulus values are in agreement with the overall average equilibrium modulus, but are smaller than the individual values from the viscoelastic analysis of the same data (data not shown); this is likely because the finite layer thickness was accounted for in the FE model but not in the viscoelastic analysis. This is particularly an issue with the thin gels, for which the indentation depth $h$ was more than $10 \%$ of the layer thickness, $l$. There is also a trend towards decreasing modulus values with increasing indentation depth in the thin gel poroelastic results, although this effect is relatively small $(<20 \%)$. Poisson's ratio increased with increasing indentation depth, and both hydraulic and intrinsic permeability values decreased with increased indentation depth.

\section{DISCUSSION}

Highly hydrated biological tissue and polymer gel materials are extremely compliant, and mechanical characterization of low-modulus materials holds several challenges. Indentation is an ideal mechanism for characterization of compliant materials, as there is no need to try to "grip" the sample as in a tensile test. However, new approaches are required for data analysis when it comes to hydrated time-dependent 
materials - the elastic-plastic contact models [26,27] typically used for nanoindentation data analysis, are completely inappropriate in this context.

Under displacement control, at a fixed displacement the load relaxes in a timedependent material. There are relaxation mechanisms in both viscoelastic and poroelastic mechanical problems, but historically little effort has gone into distinguishing between the mechanisms. The choice is typically made a priori based on knowledge of the material, for example a viscoelastic solid polymer or a poroelastic hydrated soft tissue. Here the two approaches were compared explicitly.

The length-scales probed here by nanoindentation and microindentation tests were significantly different. There was a two order of magnitude difference in the indentation depth and an order of magnitude difference in the indenter radius. As such, given the fact that the time-constant for poroelasticity, $\tau=L^{2} / G \kappa[18,21]$ contains an experimental length-scale $(L)$, it should be expected that the time constants observed in nanoindentation and microindentation were substantially different here. For larger experimental time-scales (microindentation) there was little relaxation (i.e. a larger elastic fraction, $f_{\mathrm{E}}$ ) in an experimental time-frame of tens of seconds when compared with more obvious time-dependence observed in the same time-frame in nanoindentation (Fig. 3). There is no length-scale intrinsic to viscoelasticity - as noted above, the appearance of different experimental time-constants for nanoindentation and microindentation is consistent with the existence of a length-scale associated with poroelasticity.

It is also possible to identify differences between the shapes of the relaxation curves, given the fact that the mechanisms of relaxation are physically different. We further propose to use this curve shape as an additional piece of evidence to establish the active time-dependent mechanism is active in any given experiment. This curve-shape difference illustrated in Figure 6, in which a best-fit from an FE spherical contact simulation on acrylamide gel is shown for both a poroelastic and a viscoelastic (standard linear solid) model (Figure 6a). The difference between the fits is subtle, but plotting the residuals (Figure 6b) clearly demonstrates that the poroelastic fit is superior to the viscoelastic fit in this case: the viscoelastic fit both overshoots and undershoots at different points on the experimental curve. There are thus several independent pieces of evidence to suggest a poroelastic, instead of viscoelastic, mechanism operating in these 
indentation tests. Given the emphasis on poroelastic flow, it is envisioned that timedomain, and not frequency-domain, measurements will be most suitable for nanoindentation characterization of hydrated gels and tissues.

In the current study, experimental measurements of the elastic modulus of hydrated gel materials were consistent between microindentation and nanoindentation, although numerical values of the obtained elastic modulus were larger for indentation than for homogeneous compression testing. One potential experimental factor in overstimation of elastic modulus values is the indentation depth relative to the gel layer thickness. It has been shown with FE models that poroelastic layers show an apparent stiffening effect when the layer thickness is small [28], an effect similar to that for an elastic multi-layered system. The thin gel results for microindentation (Table 1) seem to be particularly afflicted with this, since comparison of the viscoelastic analysis - which assumes bulk half-space behavior - and the poroelastic analysis for a subset of the same gels (Table 2) removes the overestimation relative to all other indentation data. The compressive values were numerically in good agreement with values of $E=0.22 \mathrm{MPa}$ reported previously [29] for similar 20\% acrylamide gels. Therefore the indentation values appear to be still slightly too large, even in thick gels or when the finite layer thickness has been accounted for. A similar effect has been observed previously in nongel polymeric systems, in which nanoindentation results consistently over-predict the elastic modulus compared with homogeneous loading [7]. It is unclear why this is the case but further investigations are clearly warranted.

Gel intrinsic permeability values, obtained from inverse FE analysis of microindentation test data, ranged from $5.6 \times 10^{-20} \mathrm{~m}^{2}$ to $1.2 \times 10^{-19} \mathrm{~m}^{2}$. These values are in direct agreement with a value of $1 \times 10^{-19} \mathrm{~m}^{2}$ previously published [30] for polyacrylamide gels of the same composition (20\%) but using macroscopic homogeneous loading experiments. This result is encouraging, as it implies that indentation tests can be set up for high-throughput poroelastic characterization, especially when modern nanoindenters with automated $\mathrm{x}-\mathrm{y}$ stage motion is available. However, each FE simulation for parameter optimization in the current study lasted for approximately 24 hours. Recently, a suggestion has been made [21], based on previous analyses of the poroelastic spherical indentation problem [31,32] that a "master curve" approach could 
Page 12 of 22

be adopted for fast identification of permeability from experimental indentation data. The original suggestion and earlier analyses [21, 31, 32] were all based on step-load creep experiments, but there is no physical reason that a similar approach could not be adopted for displacement-controlled relaxation tests under more typical experimental conditions. The rapid identification of permeability from indentation tests would allow for "permeability mapping" of biological tissues or inhomogeneous materials, similar in concept to the "modulus map" approach already being used for elastic characterization of inhomogeneous materials and tissues [33].

\section{ACKNOWLEDGMENTS:}

M. Galli was supported by Grant number PBELB-120953 from the Swiss National Science Foundation. The authors thank Z. Suo and X. Zhao of Harvard University, for helpful discussions related to the interpretation of these data. 


\section{REFERENCES:}

1. M.R. Van Landingham, N.-K. Chang, P.L. Drzal, C.C. White, S.-H. Chang, Viscoelastic characterization of polymers using instrumented indentation, I. Quasistatic testing. Journal of Polymer Science Part B: Polymer Physics. 43, 1794 (2005).

2. Ebenstein D and Pruitt L, Nanoindentation of biological materials. Nano Today 1, 26 (2006).

3. L. Cheng, X. Xia, L.E. Scriven, and W.W. Gerberich, Spherical-tip indentation of viscoelastic material, Mechanics of Mater 37, 213 (2005).

4. H. Lu, B. Wang, J. Ma, G. Huang, and H. Viswanathan, Measurement of creep compliance of solid polymers by nanoindentation. Mechanics of Time-dependent Materials 7, 189 (2003).

5. Tweedie C. and Van Vliet K., Contact creep compliance of viscoelastic materials via nanoindentation. Journal of Materials Research 21, 1576 (2006).

6. M. L. Oyen, Spherical Indentation Creep Following Ramp Loading, Journal of Materials Research, 202094 (2005).

7. Oyen ML, Sensitivity of Polymer Nanoindentation Creep Properties to Experimental Variables, Acta Materialia. 55, 3633 (2007).

8. Oyen ML and Cook RF, Load-Displacement Behavior During Sharp Indentation of Viscous-Elastic-Plastic Materials, Journal of Materials Research, 18, 139 (2003).

9. Anand L, Ames NM, On modeling the micro-indentation response of an amorphous polymer. Int. J. Plasticity 22, 1123 (2006).

10. Bembey AK, Oyen ML, Bushby AJ, Boyde A, Viscoelastic properties of bone as a function of hydration state determined by nanoindentation. Phil. Mag. 86, 5691 (2006).

11. Bembey AK, Bushby AJ, Boyde A, Ferguson VL, Oyen ML, Hydration Effects on Bone Micro-Mechanical Properties. J. Mater. Res. 21, 1962 (2006).

12. Mattice JM, Lau AG, Oyen ML, Kent RW, Spherical Indentation Load-Relaxation of Soft Biological Tissues, J. Mater. Res. 21, 2003 (2006).

13. Lau AG, Oyen ML, Kent RW, Murakami D, Torigaki T, Indentation Stiffness of Aging Human Costal Cartilage. Acta Biomaterialia 4, 97 (2008).

14. Kaufman JD, Miller GJ, Morgan EF, Klapperich CM, Time-dependent mechanical characterization of poly(2-hydroxyethyl methacrylate) hydrogels using nanoindentation and unconfined compression, Journal of Materials Research 23, 1472 (2008).

15. Huang G, Wang B, Lu H. Measurements of viscoelastic functions of polymers in the frequency-domain using nanoindentation.Mech. Time-Dep. Mater. 8, 345 (2004).

16. G.M. Odegard, T.S. Gates, H.M. Herring, Characterization of viscoelastic properties of polymeric materials through nanoindentation. Exper. Mech. 45, 130 (2005).

17. Herbert EG, Oliver WC, Pharr GM. Nanoindentation and the dynamic characterization of viscoelastic solids. J. Phys. D. Appl. Phys 41, 074021 (2008).

18. Cowin SC, Bone poroelasticity, J. Biomech. 32, 217 (1999).

19. H. W. Wang, Theory of Linear Poroelasticity with Applications to Geomechanics and Hydrogeology, Princeton University Press, Princeton, NJ (2000).

20. Lakes RS, Viscoelastic Solids. Boca Raton: CRC press, (1998). 
21. Oyen ML, Poroelastic Nanoindentation Responses of Hydrated Bone. Journal of Materials Research 23 (2008) 1307-14.

22. Yamashita J, Furman BR, Rawls HR, Wang X, Agrawal CM. The use of dynamic mechanical analysis to assess the viscoelastic properties of human cortical bone, $J$ Biomed Mater Res, 58, 47 (2001)

23. J. Cugnoni, J. Botsis, J. Sivasubramanian., J. Janczak-Rusch, Experimental and numerical studies on size and constraining effects in lead-free solder joint, Fatigue Fract. Eng. M. 30, 387 (2007).

24. M. Galli, J. Cugnoni, J. Botsis, J. Janczak-Rusch, Identification of the matrix elastoplastic properties in reinforced active brazing alloys, Compos. Part A-Appl. S. 39, 972 (2008).

25. F. Lei, J. A. Z. Szeri, Inverse analysis of constitutive models: Biological soft tissues, J. Biomech. 40, 936 (2007).

26. Field JS and Swain MV, A simple predictive model for spherical indentation, $J$. Mater. Res. 8, 297-306 (1993).

27. Oliver WC and Pharr GM, Improved technique for determining hardness and elastic modulus using load and displacement sensing indentation experiments, J. Mater. Res. 7, 1564-83 (1992).

28. Galli M and Oyen ML, Spherical indentation of a finite poroelastic coating. Applied Physics Letters 93, 031911 (2008).

29. Schramm-Baxter J, Katrencik J, Mitragotri S. Jet injection into polyacrylamide gels: investigation of jet injection mechanics. J Biomech. 37, 1181 (2004).

30. White ML, The Permeability of an acrylamide polymer gel, The Journal of Physical Chemistry 64, 1563 (1960).

31. Agbezuge LK and Deresiewicz $\mathrm{H}$, On the indentation of a consolidating half-space, Israel J. of Tech. 12, 322 (1974).

32. Selvadurai APS, Stationary damage modeling of poroelastic contact, Int. J. Solids Structures 41, 2043 (2004).

33. Cuy JL, Mann AB, Livi KJ, Teaford MF, and Weihs TP, Nanoindentation mapping of the mechanical properties of human molar tooth enamel. Arch. Oral. Biol. 47, 281 (2002). 
Page 15 of 22

Table 1: Mechanical properties of poly(acrylamide) gels measured via microindentation and nanoindentation load-relaxation tests.

\begin{tabular}{|c|c|c|c|c|c|}
\hline & $\begin{array}{l}\text { Number of } \\
\text { tests, } n\end{array}$ & $\begin{array}{l}\text { Equilibrium } \\
\text { modulus, } \\
E_{\infty}(\mathrm{MPa})\end{array}$ & $\begin{array}{l}\text { Dashpot- } \\
\text { associated } \\
\text { modulus, } \\
E_{\mathrm{D}}(\mathrm{MPa})\end{array}$ & $\begin{array}{l}\text { Elastic } \\
\text { fraction, } f_{\mathrm{E}} \\
=E(\infty) / E(0) \\
=E_{\infty} /\left(E_{\infty}+\right. \\
\left.E_{\mathrm{D}}\right)\end{array}$ & $\begin{array}{l}\text { Viscosity, } \eta \\
\text { (MPa-s) }\end{array}$ \\
\hline \multicolumn{6}{|c|}{ Thick hydrated gels $(l=4.4 \pm 0.7 \mathrm{~mm})$} \\
\hline Microindentation & 6 & $0.37 \pm 0.11$ & $0.04 \pm 0.03$ & $0.92 \pm 0.04$ & $6.7 \pm 4.9$ \\
\hline Nanoindentation & 10 & $0.37 \pm 0.11$ & $0.08 \pm 0.02$ & $0.81 \pm 0.05$ & $0.48 \pm 0.35$ \\
\hline \multicolumn{6}{|c|}{ Thin hydrated gels $(l=1.8 \pm 0.2 \mathrm{~mm})$} \\
\hline Microindentation & 8 & $0.50 \pm 0.06$ & $0.07 \pm 0.03$ & $0.88 \pm 0.04$ & $10.5 \pm 3.6$ \\
\hline Nanoindentation & 11 & $0.35 \pm 0.04$ & $0.07 \pm 0.01$ & $0.82 \pm 0.01$ & $0.26 \pm 0.04$ \\
\hline \multicolumn{6}{|c|}{ Thin dehydrated gels (nanoindentation) } \\
\hline $\begin{array}{l}\text { Ethanol- } \\
\text { dehydrated }\end{array}$ & 3 & $\begin{array}{l}145.9 \pm \\
51.9\end{array}$ & $83.4 \pm 50.3$ & $0.65 \pm 0.05$ & $\begin{array}{l}846.5 \pm \\
662.7\end{array}$ \\
\hline Air-dehydrated & 10 & $\begin{array}{l}423.9 \pm \\
255.7\end{array}$ & $\begin{array}{l}100.0 \pm \\
29.0\end{array}$ & $0.76 \pm 0.01$ & $\begin{array}{l}688.5 \pm \\
336.0\end{array}$ \\
\hline
\end{tabular}

Table 2: Permeability results for hydrated gels tested by microindentation, based on a poroelastic finite element model.

\begin{tabular}{|l|l|l|l|l|}
\hline $\begin{array}{l}\text { Indentation } \\
\text { depth, } h_{\max }\end{array}$ & $\begin{array}{l}\text { Drained } \\
\text { Elastic } \\
\text { Modulus, } E \\
(\mathrm{MPa})\end{array}$ & $\begin{array}{l}\text { Drained } \\
\text { Poisson's ratio, } \\
v\end{array}$ & $\begin{array}{l}\text { Darcy } \\
\text { (hydraulic) } \\
\text { permeability, } \kappa \\
\left(\mathrm{m}^{4} \mathrm{~N}^{-1} \mathrm{~s}^{-1}\right)\end{array}$ & $\begin{array}{l}\text { Intrinsic } \\
\text { permeability, } k \\
\left(\mathrm{~m}^{2}\right)\end{array}$ \\
\hline Thin gels & 0.365 & 0.13 & $1.24 \times 10^{-16}$ & $1.10 \times 10^{-19}$ \\
\hline $100 \mu \mathrm{m}$ & 0.329 & 0.17 & $1.30 \times 10^{-16}$ & $1.15 \times 10^{-19}$ \\
\hline $200 \mu \mathrm{m}$ & 0.332 & 0.17 & $1.16 \times 10^{-16}$ & $1.04 \times 10^{-19}$ \\
\hline $300 \mu \mathrm{m}$ & 0.301 & 0.18 & $1.11 \times 10^{-16}$ & $9.89 \times 10^{-20}$ \\
\hline $400 \mu \mathrm{m}$ & 0.298 & 0.20 & $8.48 \times 10^{-17}$ & $7.55 \times 10^{-20}$ \\
\hline $500 \mu \mathrm{m}$ & 0.323 & 0.14 & $1.09 \times 10^{-16}$ & $9.73 \times 10^{-20}$ \\
\hline Thick gels & 0.365 & 0.14 & $9.16 \times 10^{-17}$ & $8.15 \times 10^{-20}$ \\
\hline $100 \mu \mathrm{m}$ & 0.356 & 0.18 & $6.25 \times 10^{-17}$ & $5.56 \times 10^{-20}$ \\
\hline $200 \mu \mathrm{m}$ &
\end{tabular}


Page 16 of 22

\section{FIGURE CAPTIONS:}

Figure 1: Schematic illustration of the standard linear solid viscoelastic model used throughout.

Figure 2: Schematic illustration of the finite element model geometry and boundary conditions for establishing hydraulic permeability from indentation tests. The indentation depth is $h$ and the poroelastic layer thickness is $l$.

Figure 3: Experimental indentation load-time $(P-t)$ relaxation data for (a) nanoindentation on hydrated gel (b) nanoindentation on a de-hydrated gel soaked in ethanol (c) microindentation on hydrated gel.

Figure 4: Comparison between dynamic compression tests and the average results from micro- and nano-indentation tests converted to frequency-based data, illustrating (a) storage modulus, $E^{\prime}$, and (b) loss tangent, $\tan \delta$.

Figure 5: (a) Comparison between experimental and FE-identified load-time $(P-t)$ curve for a 200 micron indentation depth and (b) the corresponding residuals, computed according to Eqn. 8. At the end of the identification the two relaxation $(P-t)$ curves almost coincide, with the residuals not exceeding \pm 0.002 at any time point.

Figure 6: (a) Comparison between experimental and FE-identified poroelastic and viscoelastic load-time $(P-t)$ curves for a thin gel specimen and a 100 micron indentation depth, and (b) the corresponding residuals, computed according to Eqn. 8. In the poroelastic case the two $P$ - $t$ curves almost coincide with the residuals not exceeding +0.002 at any time point, while the quality of the viscoelastic fit is much lower with a maximum value of the residuals as large as 0.015 . 
Page 17 of 22

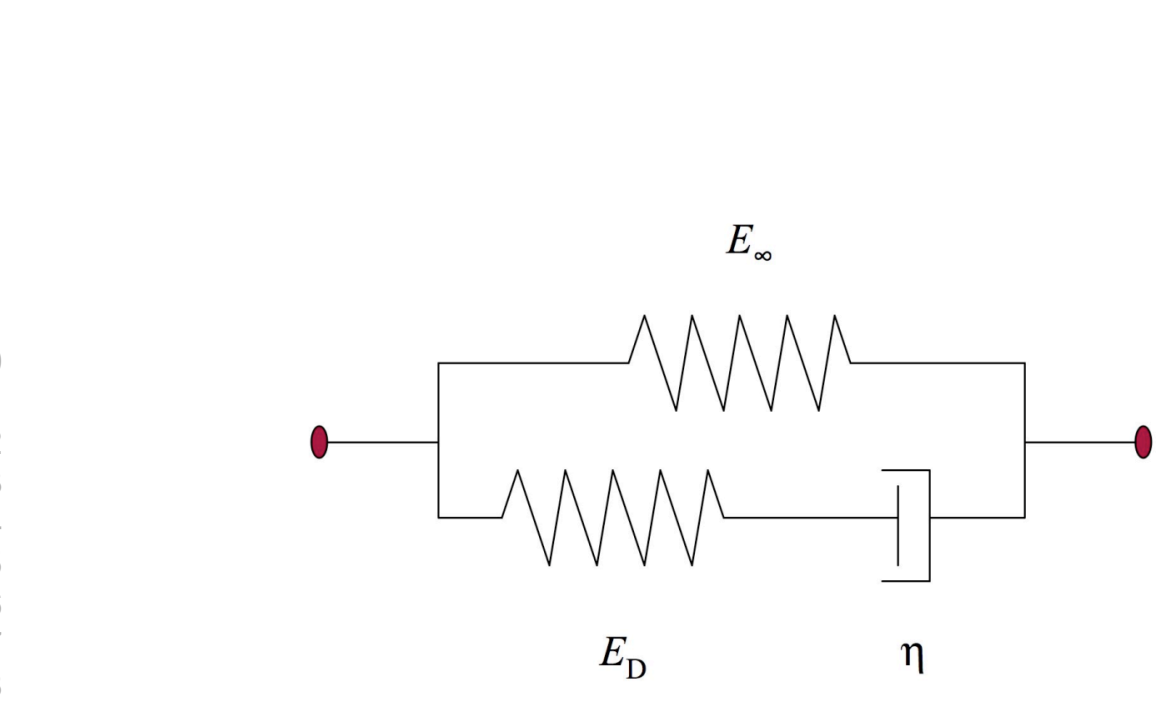

Figure 1 \\ Page 17 of 22}


Page 18 of 22

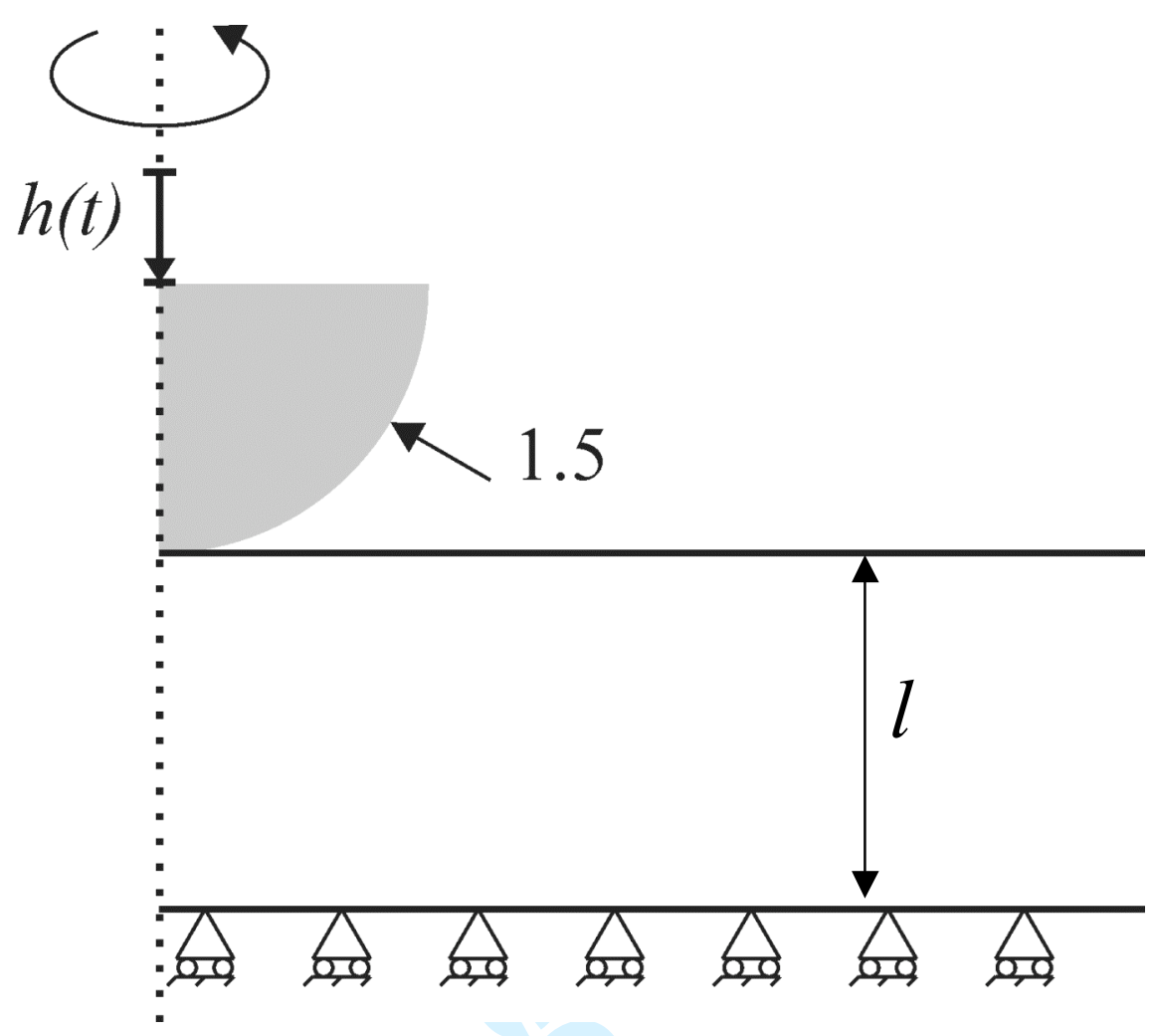

Figure 2 
Page 19 of 22
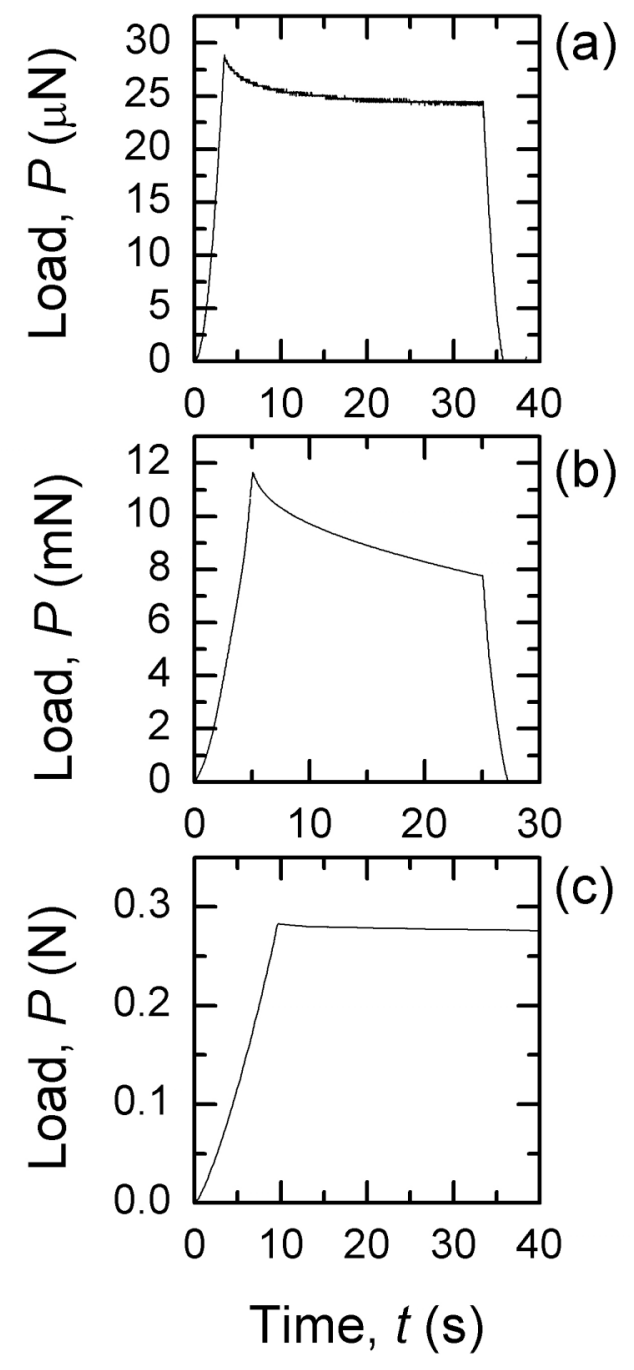

Figure 3 
Page 20 of 22

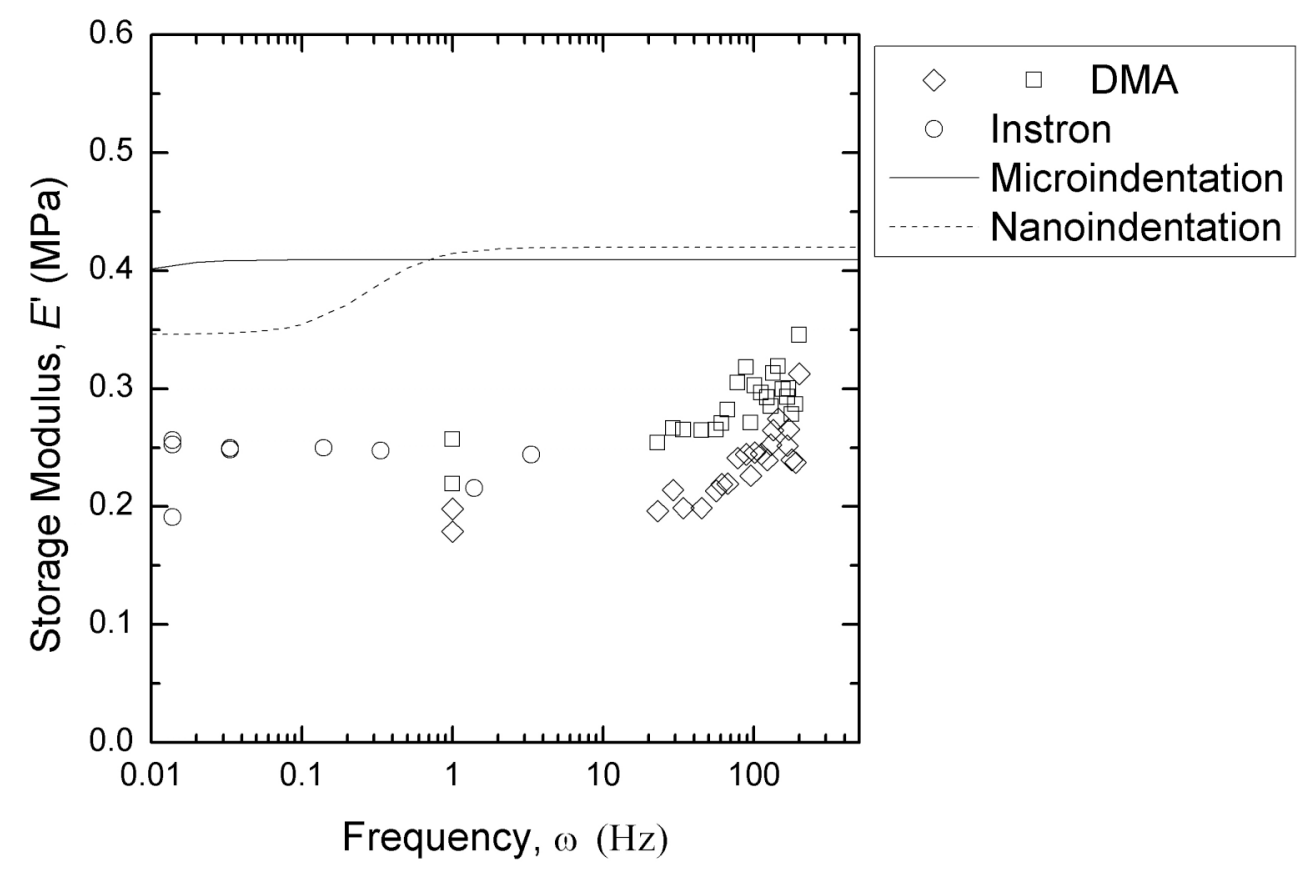

Figure 4(a)
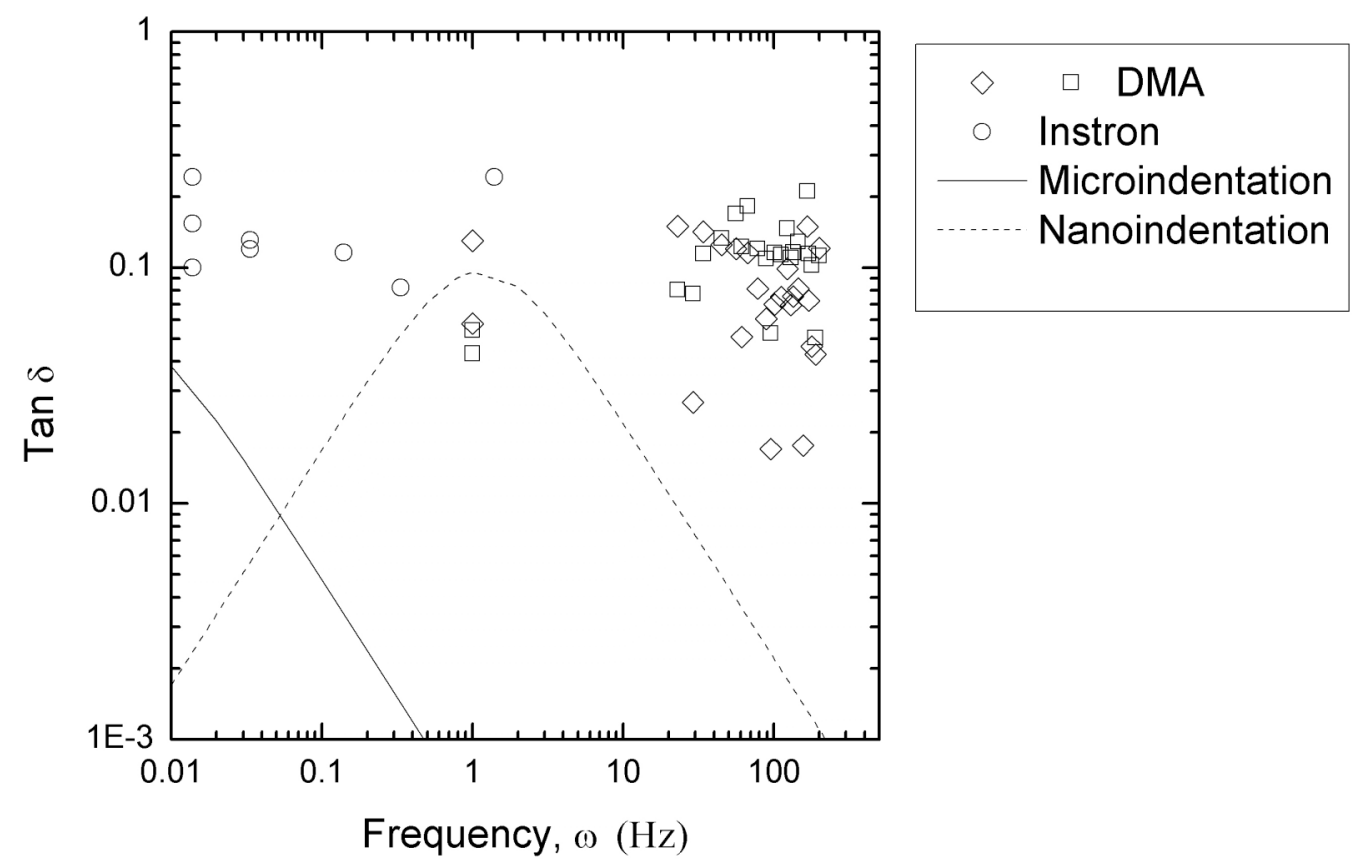

Figure 4(b) 
Page 21 of 22

(a)
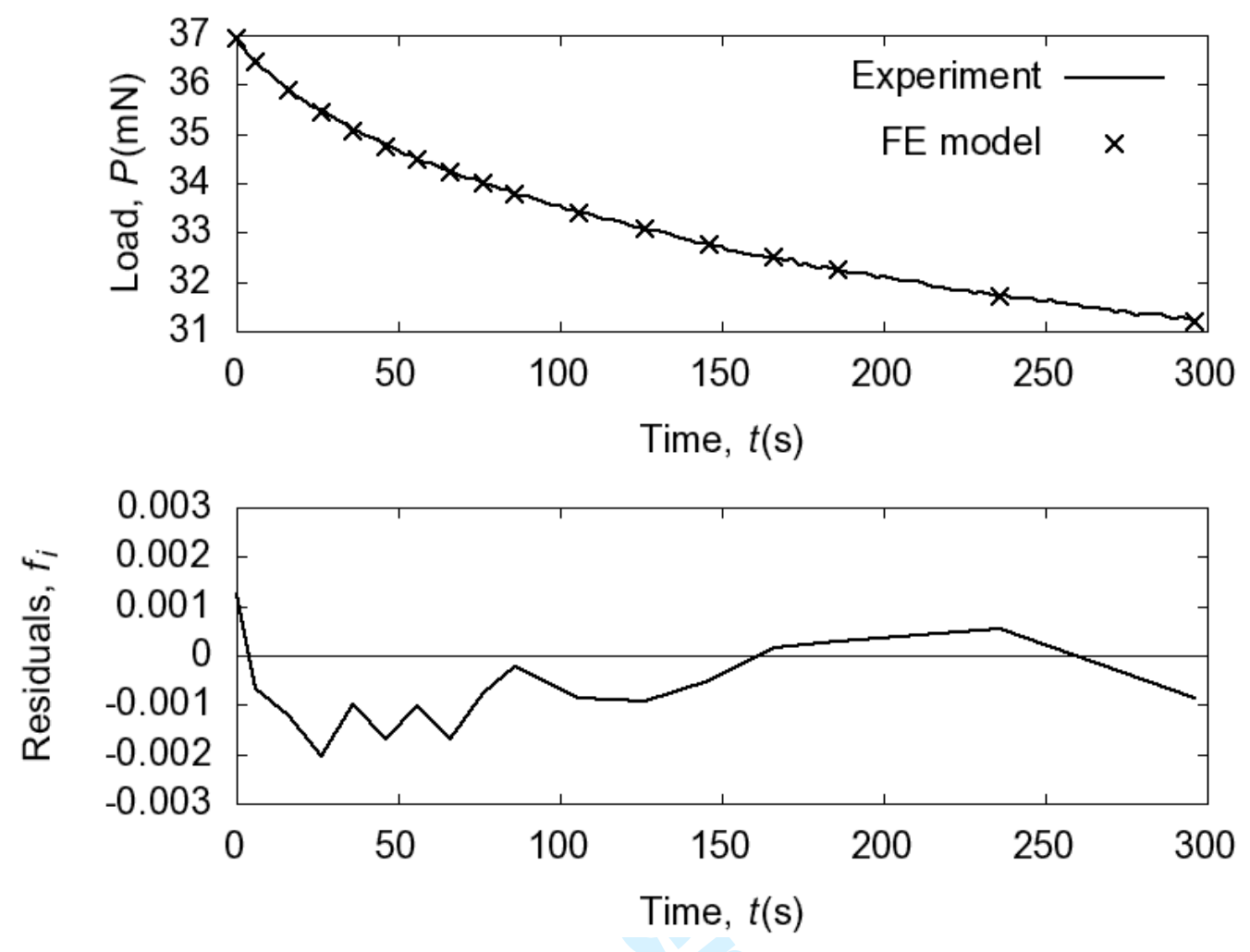

(b)

Figure 5 
Page 22 of 22

(a)
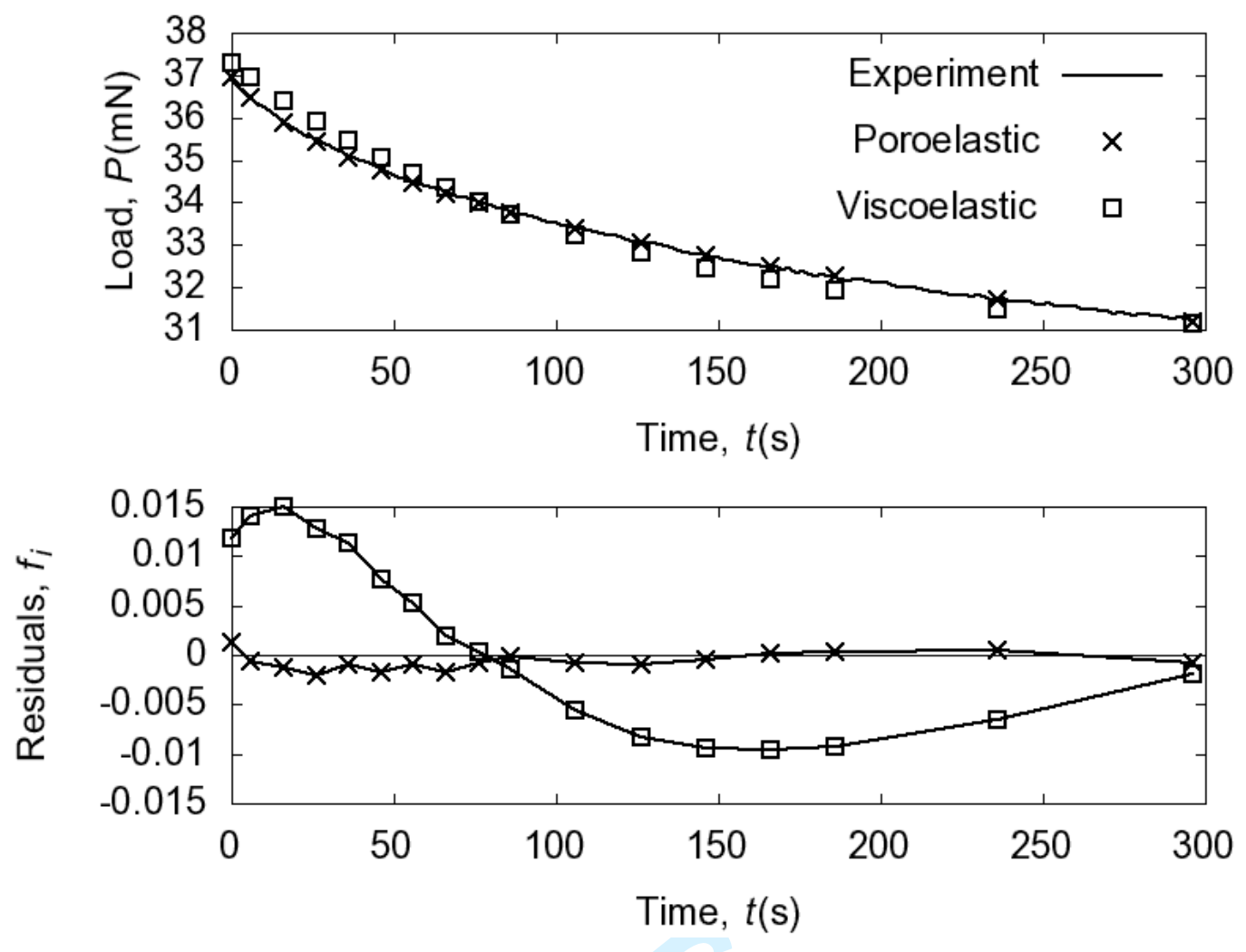

(b)

Figure 6 